\title{
Quais são as indicações geográficas brasileiras?
}

\section{What are the Brazilian Geographical Indications?}

\section{¿Cuáles son las indicaciones geográficas brasileñas?}

Patrícia Maria da Silva Barbosa, doutoranda em Biotecnologia Vegetal pela UFRJ. Endereço: Rua São Bento, $n^{\circ}$ 1, $7^{\circ}$ andar Centro. CEP: 20090-010 - Rio de Janeiro, RJ. Telefone: (21) 30373902. E-mail: pmdsbl@gmail.com.

Lucia Regina Rangel de Moraes Valente Fernandes, coordenadora geral de Indicações Geográficas e Registros do Instituto Nacional da Propriedade Industrial (Inpi). Endereço: Rua São Bento, n 1, $18^{\circ}$ andar - Centro. CEP: 20090-010 - Rio de Janeiro, RJ. Telefone: (21)3037-3327. E-mail: luciaregg@uol.com.

Celso Luiz Salgueiro Lage, especialista sênior em Propriedade Industrial em Biotecnologia do Inpi. Endereço: Rua Mayrink Veiga, $n^{\circ}$ 9, $18^{\circ}$ andar - Centro. CEP: 20090-910 - Rio de Janeiro, RJ. Telefone: (21) 3037-3934. E-mail: clslage@gmail.com.

\section{Resumo}

O presente trabalho analisa as solicitações e os registros das indicações geográficas (IGs) brasileiras feitas ao Instituto Nacional da Propriedade Industrial desde a entrada em vigor da Lei de Propriedade Industrial, em maio de 1997, até o final do ano de 2011. Os principais produtos brasileiros que buscam proteção são o café, as bebidas alcoólicas, as rochas, a água mineral, o queijo e o algodão colorido, sendo o café o responsável por 18,6\% dos depósitos nacionais. A região com o maior número de depósitos é a Sudeste. No entanto, é o Rio Grande do Sul, estado localizado na região Sul, o detentor do maior número de IGs concedidas, seis das 14. O setor com mais concessões 
até 2011 foi o de bebidas alcoólicas, com três IGs: duas para vinhos e uma para a cachaça, o que representa $21,4 \%$ das concessões.

Palavras-chave: Indicações Geográficas. Propriedade Intelectual. Denominação de Origem. Indicação de Procedência.

\section{Abstract}

This paper analyses the requests and registrations of Geographical Indications (IGs) made to the Brazilian National Institute of Industrial Property since implementing the Law of Industrial Property during the period of May 1997 until the end of 2011. We discovered that the main Brazilian products seeking protection are coffee, alcoholic beverages, rocks, mineral water, cheese and colored cotton. Coffee is responsible for $18.6 \%$ of the national applications. The geographic region with the highest number of registration requests is the Southeast region. However, Rio Grande do Sul, located in the South, is the state with the highest number of granted IGs: 6 of 14. The sector with the most IGs is the alcoholic beverage industry, with three IGs (two for wine and one for cachaça), which represent $21.4 \%$ of the concessions.

Keywords: Geographical Indications. Intellectual Property. Designation of Origin. Indication of Source.

\section{Resumen}

Este trabajo analiza las solicitudes y los registros de las indicaciones geográficas (IGs) brasileñas solicitados al Instituto Nacional de Propiedad Industrial de Brasil desde la entrada en vigor de la Ley de Propiedad Industrial en mayo de 1997 hasta finales de 2011. Los principales productos brasileños que buscan protección son el café, las bebidas alcohólicas, rocas, agua mineral, queso y algodón de color. El café es responsable por el 18,6\% de los depósitos nacionales. La región con el mayor número de depósitos es la sureste. Sin embargo, 
Rio Grande del Sur, en la región sur, tiene la mayor cantidad de IGs concedidas, seis de un total de 14. El sector con más concesiones hasta el 2011 es la industria de bebidas alcohólicas, con tres IGs: dos para vinos y una para cachaza, lo que representa el $21,4 \%$ de las concesiones.

Palabras clave: Indicaciones Geográficas. Propiedad Industrial. Denominación de Origen. Indicación de Procedencia.

\section{Introdução}

Quando se menciona apropriação, propriedade intelectual, biodiversidade e biotecnologia, a primeira associação comumente feita é com a proteção por meio de patentes. Diversos autores, tais como Varella (1997), Figueiredo e Penteado (2006), Lima, Baptista e Bensusan (2003) e Moreira e Antunes (2004), entre outros, têm abordado o assunto, discutindo as características dessa proteção. Porém, a propriedade intelectual não se restringe apenas ao sistema patentário. Na verdade, ela possui outros ativos ainda pouco estudados que, pouco a pouco, estão sendo cogitados como possibilidades de ferramentas de proteção de biodiversidade e ainda da biotecnologia: são os sinais distintivos de uso coletivo indicações geográficas (IGs) e marcas coletivas. Larson (2007) e Rangnekar (2004) abordaram o assunto recentemente com enfoque na relação das IGs, e é sobre esse aspecto da propriedade intelectual que recai o interesse dos autores no momento.

No presente artigo, apresentamos parte de pesquisa de doutorado em andamento na Pós-Graduação em Biotecnologia Vegetal da UFRJ; por questões práticas, optou-se por abordar apenas um dos dois sinais distintivos acima citados. A opção por nos atermos apenas às indicações geográficas tem por principal motivo ser ele o sinal estudado, até o momento, na corrente pesquisa.

Nosso principal objetivo aqui é traçar um perfil das IGs brasileiras por meio do estudo das solicitações de registro nacionais feitas ao Instituto Nacional da Propriedade Industrial (Inpi). Tem- 
se o intuito de identificar quais são os produtos/serviços brasileiros que estão em busca desse tipo de proteção ainda pouco conhecida, assim como demonstrar quais receberam o registro. Apresentaremos também quais os estados que mais requerem e quais os que mais receberam a proteção. 0 escopo desses registros também será alvo de exame.

A fonte de dados do presente trabalho foi o Inpi, autarquia federal e órgão oficial de registro desse ativo de propriedade intelectual. A pesquisa foi possivel tendo em vista a disseminação de informações por meio da página oficial na internet dos dados sobre depósitos e concessões de indicações geográficas (IGs) 1 .

Examinaram-se os depósitos realizados desde a entrada em vigor da Lei da Propriedade Industrial (LPI), nº 9.279, em maio de 1997, até o final do ano de 2011. Todos os dados foram trabalhados com o uso do programa Excel 2007. A metodologia exploratório-descritiva (GIL, 1994) foi a utilizada, visando proporcionar uma visão geral do cenário das IGs requeridas no Brasil, servindo de base para estudos posteriores.

Inicialmente, apresentam-se as principais características das IGs segundo a legislação nacional em vigor. Em seguida, passa-se à análise dos dados coletados, em que será verificada a distribuição anual dos depósitos e identificados as regiões e os estados de acordo com o número de depósitos, assim como quais os produtos/serviços requeridos. Realizaremos um comparativo com dados de Barbosa (2010) visando descrever o comportamento existente na época do estudo até o final do ano de 2011 no setor e identificar as possíveis modificações do cenário, caso ocorram.

Na sequência, traçaremos um perfil das IGs concedidas até 2011 com a descrição dos produtos/serviços protegidos, assim como a identificação de a que estados pertencem. Finalizaremos com as considerações a respeito dos resultados encontrados. 


\section{Indicações geográficas (IGs) - principais características}

A legislação vigente no Brasil é a Lei n 9.279, de 14 de maio de 1996. Ela entrou em vigor em 1997 e será doravante denominada LPI.

Em seus artigos 177 e 178, a LPI dispõe:

Art. 177 - Considera-se indicação de procedência o nome geográfico de país, cidade, região ou localidade de seu território, que se tenha tornado conhecido como centro de extração, produção ou fabricação de determinado produto ou de prestação de determinado serviço.

Art. 178 - Considera-se denominação de origem o nome geográfico de país, cidade, região ou localidade de seu território, que designe produto ou serviço cujas qualidades ou características se devam exclusiva ou essencialmente ao meio geográfico, incluídos fatores naturais e humanos.

Dessa forma, a LPI não define o que é a indicação geográfica propriamente dita e apenas a classifica em duas espécies: a indicação de procedência (IP) e a denominação de origem (DO).

As definições conceituais e o uso da terminologia no campo das IGs é recorrentemente motivo de dificuldades ao longo da história e ainda entre os países. Barbosa (2003) considera que as IGs são um sinal de uso exclusivo de produtores ou prestadores de serviço de uma determinada área. Tais produtores obtêm o direito de exclusividade por meio do registro, seja na espécie indicação de procedência ou denominação de origem. Tal entendimento é compativel com o artigo 182 da LPI, que dispõe que o uso da indicação geográfica é restrito aos produtores e prestadores de serviço estabelecidos no local, exigindose, ainda, em relação às denominações de origem, o atendimento de requisitos de qualidade.

O mesmo autor descreve que a IP é a IG que visa identificar a origem de um determinado produto ou serviço, de região específica de produção com reconhecida reputação, de modo a distinguir tal produto ou serviço de outros similares no mercado. Para ele, a DO, por sua vez, vai além da notoriedade, pois nessa espécie as características 
específicas do produto ou serviço são atribuídas a fatores peculiares, que podem ser naturais do meio geográfico e/ou características humanas. Nesse sentido, as características peculiares relacionadas a condições naturais podem ser, por exemplo, clima, temperatura, altitude, umidade e composição do solo, entre outras, enquanto as humanas compreendem saberes e práticas culturais tradicionalmente transmitidas ao longo de gerações (BARBOSA, 2003).

Assim temos, grosso modo, que a IP é a expressão ou sinal que indica a origem geográfica específica de um produto ou serviço. A DO também é expressão ou sinal que indica a origem geográfica específica de um produto ou serviço, assim como a IP, porém na DO o produto ou serviço possui tais características particulares devido ao meio geográfico em que se encontra, como o tipo de solo, que confere sabores diferenciados a uma uva produtora de vinho. Nessa proteção, podem ser incluídos fatores humanos singulares como as condições específicas de produção. Por exemplo, a forma ímpar de manusear o leite para transformá-lo em queijo.

A LPI determina que a proteção é devida especificamente "aos nomes geográficos" (artigos 177 e 178 acima citados). No entanto, os TRIPs (Trade-Related Aspects of Intellectual Property Rights)2, legislação internacional regente do tema, dispõe em seu artigo 22:

Geographical indications are, for the purposes of this Agreement, indications which identify a good as originating in the territory of a Member, or a region or locality in that territory, where a given quality, reputation or other characteristic of the good is essentially attributable to its geographical origin (grifo dos autores).

Temos então, em tradução livre, que os TRIPs descreve as IGs como indicações que identificam um bem (a good) como originário do território, ou de uma região ou de uma localidade, e não um nome geográfico como na LPI. Dessa forma, o Brasil é mais restritivo ao condicionar seus registros a nomes geográficos.

Disponivel em http:// www.wto.org/english/ tratop_e/trips_e/trips_e. htm.
Esse é um ponto que costuma causar discussões e pedidos de modificação na LPI. É comum encontrar, ao longo do País, regiões 
que são conhecidas e nomeadas pela população em geral, mas que não são legalmente regiões geopolíticas. Um exemplo que podemos citar é o caso da Costa do Cacau. A região, que tem cerca de 180kms, localizada entre os municípios de Itacaré e Canavieiras na Bahia, é tradicionalmente reconhecida pelo público consumidor de cacau e chocolate como uma região de cacau de qualidade. No entanto, apesar da fama e do reconhecimento público, a Costa do Cacau não é uma região geopolítica legalmente reconhecida e, portanto, exige, por parte do órgão oficial que venha a ser responsável pela delimitação da área geográfica, um entendimento maior e a adequação aos requisitos exigidos pela Resolução Inpi nº 075 de 28/11/2000.

É realmente um tema que merece mais reflexões. Sem dúvida, a legislação impacta os anseios e a necessidade dos cidadãos e, ao mesmo tempo, é impactada. O indivíduo tem papel fundamental nesse processo de mudanças, sendo tratado por Sen (2000 apud BRUCH; AREAS, 2011) como agente do desenvolvimento. Ao mesmo tempo, a existência de casos práticos, que geram reflexões, serve de experiência e deve ser considerada para as modificações que por ventura venham a ser realizadas na legislação. Dentro desse contexto, observa-se a necessidade de aperfeiçoamento constante, tendo em vista que a sociedade é mutável.

Os mesmos artigos 177 e 178 apresentam ainda outra importante similaridade com relação aos TRIPs: estendem a possibilidade de proteção a serviços, estendendo o conceito de bens (good) às coisas materiais ou imateriais que têm valor econômico e que podem servir de objeto para uma relação jurídica³ ${ }^{3}$.

Esse é mais um ponto que levanta discussões no meio. A origem histórica das IGs as remete tradicionalmente a produtos de origem agropecuária (PINHO, 1996; RAMELLO, 2006). Devido à ausência de um caso de concessão de IG de serviços no País, existe a discussão sobre de que forma uma IG de serviço poderia ser consolidada. Em 2008, foi feito um depósito para serviços de tecnologia da informação - IG 201103 “Porto Digital” -, mas ele encontra-se ainda pendente de análise pelo Inpi.
${ }^{3}$ Para que o bem seja objeto de uma relação jurídica, é preciso que ele apresente os seguintes caracteres: idoneidade para satisfazer um interesse econômico, gestão econômica autônoma e subordinação jurídica ao seu titular. Fonte: http:// www.centraljuridica.com/ doutrina/58/direito_civil/ dos_bens.html. 
Considera-se a hipótese de uma IG que se destine a serviços de turismo - existem diversas regiões no País em que o turismo é reconhecidamente o principal fator associado ao nome de uma região. Citemos aqui o caso de Bonito. Localizado no sudoeste do estado de Mato Grosso do Sul, é uma cidade turística atraente devido a suas cachoeiras, seus rios e lagos de água cristalina e sua natureza exuberante. A cidade oferece diversos passeios, tais como trilhas, passeios de bote, esportes radicais, como rapel e rafting. Não poderia ser o caso de uma potencial IG de serviço? Esse é apenas um exemplo e podem-se cogitar outros na mesma linha de raciocínio. Seria o caso de Fernando de Noronha, Porto de Galinhas, etc.

Destaca-se ainda que a IG possui outra notável diferença com relação aos demais ativos intangiveis protegidos pela propriedade intelectual: uma vez concedida, vigora indeterminadamente, estando condicionada somente ao período da existência do produto ou serviço reconhecido por suas características particulares. Dessa forma, não existe obrigatoriedade de renovação do registro, característica presente em quase todos os demais ativos, tais como marcas e patentes.

A LPI também determina que não são suscetiveis de registro os nomes geográficos que houverem se tornado de uso comum, designando produto ou serviço (artigo 180). Aqui se enquadram exemplos internacionais como a até hoje comumente utilizada água de colônia, cuja origem é de Koln (ou Colônia, cidade alemã), a cerveja pilsen (Pilsen é uma cidade da República Tcheca), entre tantos outros (SOARES, 2007).

No Brasil, tivemos um caso representativo desse uso comum: foi o caso da bebida Cognac. A expressão Cognac foi requerida no Brasil como DO por meio do processo IG 980001 em março de 1998 por um consórcio de regiões francesas. Em seguida, os produtores de bebidas brasileiros, representados pela Associação Brasileira de Bebidas (Abrabe), entraram com representação junto ao Inpi demonstrando que já utilizavam a palavra conhaque há aproximadamente cem anos e de boa fé (SOARES, 2007). Por esse motivo, a justiça decidiu permitir o uso da expressão conhaque pelos produtores locais, desde 
que ressalvassem no rótulo a origem do produto4. Posteriormente, o Inpi realizou a concessão do registro Cognac, publicada na Revista da Propriedade Industrial (RPI) n 1527 em 2000, e, dessa forma, Cognac é hoje uma denominação de origem protegida no Brasil, e somente os produtores localizados na região podem utilizar essa grafia no País.

Esse tema de uso comum/genérico suscita importante questionamento: como identificar se o nome geográfico tornou-se genérico, confundindo-se com o próprio produto ou serviço?

Podemos citar, como exemplo, o caso do queijo de minas. Originalmente, ele começou a ser produzido no estado de Minas Gerais e ganhou fama. No entanto, não houve, à época, a iniciativa dos primeiros produtores em agregar o saber fazer do queijo ao seu estado de origem. Atualmente, esse queijo pode ser feito em qualquer parte do nosso País, sendo denominado queijo minas, e tendo, portanto, tal expressão se tornado designativa de um determinado tipo de queijo. Dessa forma, por ter se tornado de uso comum, Minas não pode mais ser requerida como indicação geográfica para queijo. No entanto, ainda pode-se requerer a IG para o nome geográfico de uma determinada região, cidade e/ou município que comprove a forma de produção ou um queijo minas diferenciado. Esse é o caso de Serro, queijo minas artesanal produzido na região centro-nordeste de Minas Gerais. Reconhecido em dezembro de 2011, tornou-se a $14^{\mathrm{a}}$ IG brasileira, como veremos mais adiante.

No artigo 181 da LPI temos que "o nome geográfico que não constitua indicação de procedência ou denominação de origem poderá servir de elemento característico de marca para produto ou serviço, desde que não induza a falsa procedência”.

O artigo explicita que nomes geográficos que não possuam notoriedade vinculada aos produtos ou serviços que se deseja identificar poderão ser registrados. Dessa forma, podemos ter o registro da marca Rio de Janeiro para autorrádios e toca fitas. Nesse aspecto, cabe a reflexão quanto à subjetividade atribuída à análise da notoriedade.
4 Decisão judicial MS. 0003187:93 - DF j:29/11/1994, $1^{\text {a }}$ turma DJ 13/02/1995, pg. 02190. Disponivel em: <http://uj.novaprolink.com. br/doutrina/1514/DAS_ MARCAS_E_PATENTES>. Acesso em: jun. 2012. 
No entanto, é importante ressaltar que, uma vez registrado o nome geográfico como IG, ele não pode ser registrado como marca para produtos ou serviços que guardem relação com o escopo protegido pela IG (LPI, art. 124, inciso IX).

O inverso, isto é, a proibição de uma marca registrada ser impeditiva de um registro de IG, não se encontra previsto na LPI. No entanto, o primeiro caso lidando com essa situação aconteceu recentemente. Trata-se do caso de Salinas para a aguardente de cana tipo cachaça reconhecida como IG em outubro de 2012. A marca individual Salinas já era registrada no Inpi desde 1993. Esse é um ponto que merece mais reflexões.

A competência legal do Inpi sobre as questões relativas às IGs está prevista na LPI, parágrafo único do artigo 182: "o INPI estabelecerá as condições de registro das indicações geográficas". Em 28 de novembro de 2000, o Inpi publicou a Resolução Inpi $n^{\circ}$ 075 com o intuito de estabelecer os procedimentos de registro de IG, quando determina que o registro deverá referir-se a um único nome geográfico. A resolução elenca ainda quais os documentos necessários para instruir o depósito, tais como:

- instrumento oficial de delimitação da área geográfica;

- elementos que comprovem ter o nome geográfico se tornado conhecido como centro de extração, produção ou fabricação do produto ou de prestação do serviço;

- elementos que comprovem a existência de uma estrutura de controle sobre os produtores ou prestadores de serviços que tenham o direito ao uso exclusivo da indicação de procedência, bem como sobre o produto ou a prestação do serviço distinguido com a indicação de procedência; e

- elementos que comprovem estarem os produtores ou prestadores de serviços estabelecidos na área geográfica demarcada e exercendo, efetivamente, as atividades de produção ou de prestação do serviço; entre outros.

Para o depósito de uma DO é necessário também apresentar documentos que atestem que as características específicas dos 
produtos ou serviços a serem assinalados devem-se ao meio geográfico, assim como a existência de uma estrutura de controle para assegurar a qualidade desses produtos e serviços, conforme disposto pelo artigo 182 da LPI: “o uso da indicação geográfica é restrito aos produtores e prestadores de serviço estabelecidos no local, exigindo-se, ainda, em relação às denominações de origem, o atendimento de requisitos de qualidade".

Importante observar que, embora haja uma entidade específica como titular da IG junto ao Inpi, a titularidade real dela pertence a todos os produtores residentes na região geográfica reconhecida, sejam eles parte integrante ou não da entidade titular. No entanto, existe a obrigatoriedade do atrelamento aos critérios específicos do regulamento técnico, já que eles é que conferem ao produto suas características singulares.

\section{Análise dos depósitos de pedidos de registro de IGs nacionais requeridos de 1997 até dezembro de 2011}

a. Distribuição anual das IGs nacionais

O Gráfico 1 demonstra o comportamento dos depósitos de pedidos de registros de IG no Inpi ao longo dos anos, desde a entrada em vigor da LPI em 1997 até dezembro de 2011 - e, para tal, a data de depósito foi o critério temporal escolhido. 


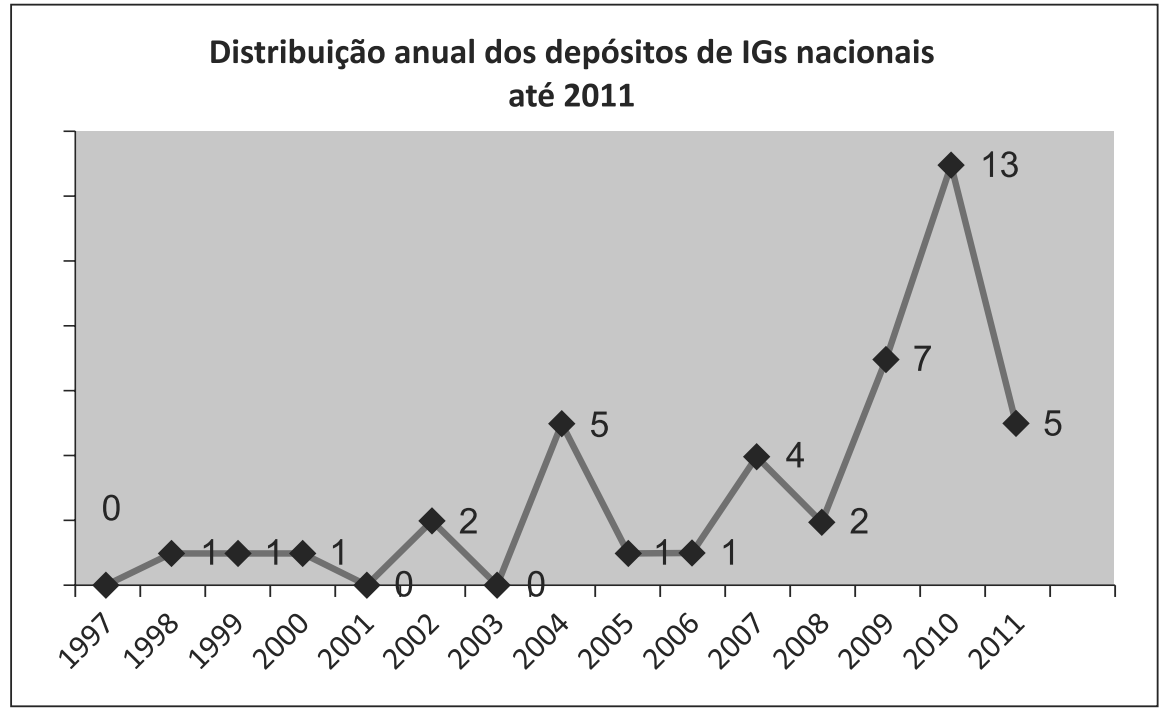

Fonte: www.inpi.gov.br. Elaboração própria.

\section{Gráfico 1. Distribuição anual dos depósitos de IGs nacionais requeridas ao Inpi até 2011}

Por meio do exame do Gráfico 1, podemos verificar que 2010 foi o ano mais expressivo em relação ao número de depósitos, quando se verificou o depósito de 13 IGs, o maior número de depósitos em todo o período de estudo. No entanto, conforme demonstrado pelo Gráfico 1, essa curva não é do tipo crescente, pois, no ano seguinte a esse pico, em 2011, tivemos somente cinco depósitos, retornando assim aos mesmos patamares de 2004. Tal comportamento chama a atenção, e uma das hipóteses para essa variação é a de que o setor ainda se encontra extremamente dependente das ações institucionais de fomento de órgãos governamentais ou não e de capacitação na proteção de ativos intangiveis. No entanto, ainda não houve tempo hábil para um estudo mais aprofundado dessa hipótese, o que nos deixa apenas no campo da suposição.

A título de contextualização histórica, consideramos oportuno informar que o primeiro depósito de pedido de registro de IG nacional, depósito IG980002, foi um pedido mineiro, na espécie DO. Tratava-se de Cerrado para o produto café. Foi feito pelo Conselho das Associações dos Cafeicultores do Cerrado em 20 de maio de 1998. Esse depósito 
foi arquivado em 05/1999 por não atender aos requisitos legais. Ainda em 1999, o Conselho realizou novo depósito, o IG990001, dessa vez com o nome de Região do Cerrado Mineiro e para a espécie IP. Ele foi concedido em 2005, tornando-se a segunda IG nacional reconhecida, pois a primeira foi Vale dos Vinhedos para vinhos em 19/11/2002.

\section{b. Distribuição por estados}

No Gráfico 2, temos a distribuição estadual de depósitos de IGs.

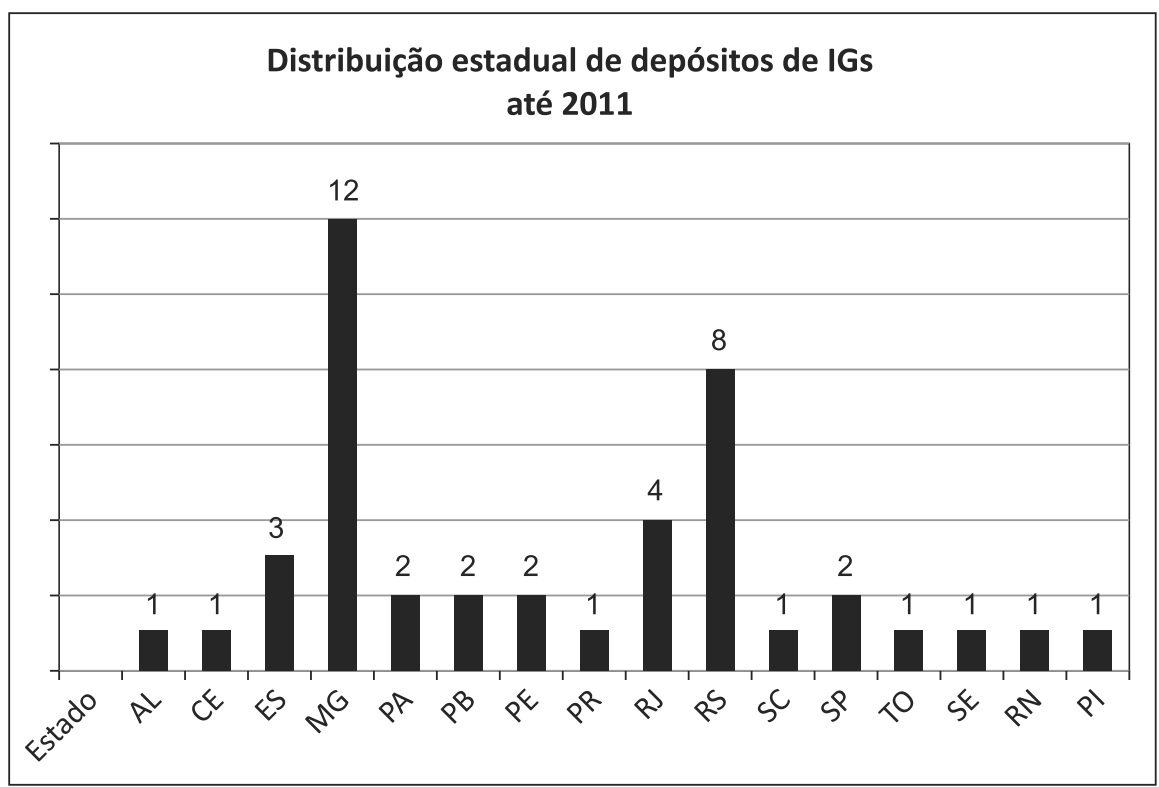

Fonte: INPI, 2012. Elaboração própria.

Legenda: CE: Ceará; ES: Espírito Santo; MG: Minas Gerais; PA: Pará; PB: Paraíba; PR: Paraná; RJ: Rio de Janeiro; RS: Rio Grande do Sul; SP: São Paulo; TO: Tocantins.

\section{Gráfico 2. Distribuição do número de depósitos por estado}

Esse gráfico demonstra que Minas Gerais e Rio Grande do Sul são os estados com o maior número de depósitos, 12 e oito, respectivamente. Isto é, 20 dos 43 depósitos pertencem a apenas dois estados, o que corresponde a $46,51 \%$ de todos os depósitos de IGs nacionais.

Nesse ponto, em que analisamos a participação dos estados brasileiros, é importante observar que a IG 200701 de 31/08/2007 do 
Vale do Submédio do São Francisco é o único depósito que pertence a dois estados, pois abrange a região da Bahia e do estado de Pernambuco. No intuito de evitar distorções, o estado da Bahia está ausente do gráfico e Pernambuco foi contabilizado como o titular desse depósito por ter sido o estado do endereço do requerente, o Conselho da União das Associações e Cooperativas dos Produtores de Uvas de Mesa e Mangas do Vale do Submédio do São Francisco. Dessa forma, Pernambuco aparece como detentor de dois depósitos, tendo em vista que efetuou um novo depósito, dessa vez abrangendo apenas seu estado. Esse novo depósito destina-se a uma IG de serviço, o Porto Digital, para serviços de tecnologia da informação (comentado anteriormente).

Além do Porto Digital, acima citado, o Inpi já recebeu outros três depósitos em que o escopo de proteção é relativo a serviço. São eles: Água Mineral Natural Terra Alta, IG 200401, em 05/01/2004; Água Mineral Natural Terra Alta; e Região do Município de Serra Negra do Estado de São Paulo (IG 200405, de 28/12/2004, para água mineral, malhas, artesanato, hotéis e turismo, todos serviços relativos à produção de água mineral). Todos os depósitos foram arquivados por inconsistências na documentação.

O último depósito efetuado até dezembro de 2011 pertence ao estado do Rio Grande do Norte. Trata-se de Mossoró, IG 201108, em 28/11/2011, para melão na espécie indicação de procedência.

\section{b.1 Comparativo do comportamento dos estados brasileiros}

Na Tabela 1, temos um comparativo do comportamento dos estados brasileiros em dois períodos. Na apresentação dessa tabela e das seguintes comparativas, as duas primeiras colunas trazem dados relativos ao período de maio de 1997 a agosto de 2010, oriundos de Barbosa (2010). Nas duas colunas seguintes, temos os dados atualizados, referentes ao período de maio de 1997 a dezembro de 2011. 
Tabela 1. Tabela comparativa dos depósitos dos estados brasileiros

\begin{tabular}{|c|c|c|c|c|}
\hline ESTADO & $\begin{array}{c}N^{\circ} \mathrm{DE} \\
\text { DEPÓSITOS ATÉ } \\
08.10\end{array}$ & $\begin{array}{c}\text { PARTICIPAÇÃO } \\
\text { NO TOTAL (\%) }\end{array}$ & $\begin{array}{c}N^{\circ} \text { DE } \\
\text { DEPÓSITOS } \\
\text { ATÉ } 12.11\end{array}$ & $\begin{array}{c}\text { PARTICIPAÇÃO } \\
\text { NO TOTAL (\%) }\end{array}$ \\
\hline$A L$ & & 0 & 1 & $2 \%$ \\
\hline CE & 1 & $3 \%$ & & $2 \%$ \\
\hline ES & 3 & $9 \%$ & & $7 \%$ \\
\hline MG & 9 & $28 \%$ & 12 & $29 \%$ \\
\hline PA & 2 & $6 \%$ & & $5 \%$ \\
\hline PB & 2 & $6 \%$ & & $5 \%$ \\
\hline$P E$ & & $0 \%$ & 1 & $2 \%$ \\
\hline $\mathrm{PE} / \mathrm{BA}$ & 1 & $3 \%$ & & $2 \%$ \\
\hline PR & 1 & $3 \%$ & & $2 \%$ \\
\hline RJ & 4 & $12 \%$ & & $9 \%$ \\
\hline RS & 7 & $21 \%$ & 8 & $20 \%$ \\
\hline SC & 1 & $3 \%$ & & $2 \%$ \\
\hline SP & 1 & $3 \%$ & 2 & $5 \%$ \\
\hline TO & 1 & $3 \%$ & & $2 \%$ \\
\hline SE & & 0 & 1 & $2 \%$ \\
\hline RN & & 0 & 1 & $2 \%$ \\
\hline $\mathrm{PI}$ & & 0 & 1 & $2 \%$ \\
\hline Total & 33 & & 43 & \\
\hline
\end{tabular}

Fonte: INPI, 2012. Elaboração própria.

A primeira importante informação que a Tabela 1 apresenta é que o número de estados depositantes cresceu. Quatro estados sem nenhum depósito até agosto de 2010 fizeram suas primeiras incursões em IGs. Foram eles: Alagoas, Sergipe, Rio Grande do Norte e Piauí. Cada um desses estados realizou apenas um depósito.

Analisando o comportamento dos estados presentes desde o primeiro estudo, relativo à sua participação no total, Minas Gerais foi o único estado a ter aumento de sua participação e passou a ser responsável por $29 \%$ do total de depósitos ao realizar três novos no 
período. Isso correspondeu ao incremento de 1\% na sua participação. Dessa forma, Minas permaneceu com a liderança no ranking estadual de número de depósitos de IGs.

No entanto, Rio Grande do Sul e Rio de Janeiro, apesar de manterem as posições anteriores alcançadas em 2010, de $2^{\circ}$ e $3^{\circ}$ maiores depositantes, tiveram redução em suas participações, em $1 \%$ e 3\%, respectivamente. Isso porque o estado do Rio Grande do Sul efetuou apenas um novo depósito no segundo período, enquanto o Rio de Janeiro não depositou nenhum.

\section{c. Distribuição regional}

De posse dos dados dos estados, podemos então passar à análise da distribuição regional, segundo o Gráfico 3.

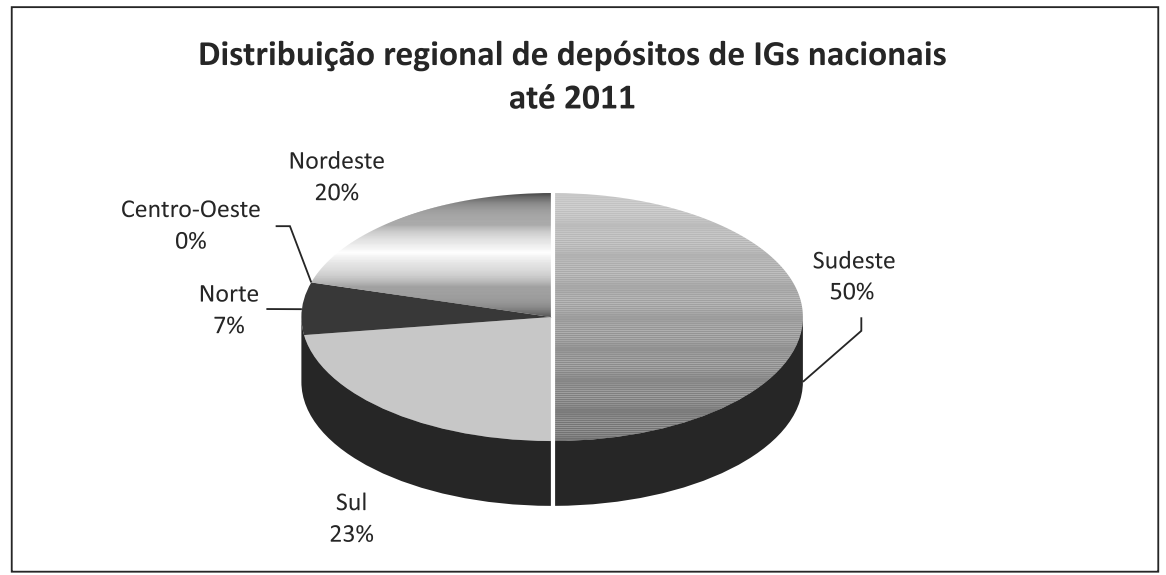

Fonte: INPI, 2012. Elaboração própria.

\section{Gráfico 3. Distribuição regional de depósitos de IGs nacionais até 2011}

Seu exame nos permite verificar que a região Sudeste foi a que mais depositou IGs, sendo responsável por 50\% deles. Conforme descrito acima, Minas Gerais foi o estado com o maior número de depósitos.

Em segundo lugar, encontramos a região Sul, respondendo por 23\% dos depósitos. O Rio Grande do Sul foi o estado que mais depositou pedidos de registro dentro da região, oito no total. 
Em terceiro lugar, temos o Nordeste com 20\%. Nessa região, Pernambuco foi o estado predominante, ao ter dois depósitos.

Em quarto lugar ficou a região Norte com $7 \%$ de participação total, sendo o estado do Pará o responsável por essa presença, ao ter realizado dois depósitos. Infelizmente, há dois arquivamentos por inconsistência na documentação. Cabe a ressalva que, caso haja interesse, um novo depósito pode ser efetuado, a exemplo da Região do Cerrado Mineiro e da Paraíba.

Por fim, verificamos que a região Centro-Oeste foi a única que não realizou nenhum depósito de IGs durante o período em análise.

\section{c. 1 Comparativo do comportamento das regiões brasileiras}

A exemplo do que foi feito com os estados acima, na Tabela 2 apresentamos o comparativo do comportamento das regiões brasileiras. Da mesma forma, nas duas primeiras colunas, temos os dados de Barbosa (2010), correspondentes a 2010, e nas duas colunas seguintes temos os dados de maio de 1997, atualizados até dezembro de 2011.

Tabela 2. Comparação do número de depósitos de IGs por região

\begin{tabular}{|l|c|c|c|c|}
\hline \multicolumn{1}{|c|}{ REGIÃO } & $\begin{array}{c}\mathbf{N}^{\circ} \text { DE } \\
\text { DEPÓSITOS } \\
\text { ATÉ 08.10 }\end{array}$ & $\begin{array}{c}\text { PARTICIPAC̄ÃO } \\
\text { NO TOTAL (\%) }\end{array}$ & $\begin{array}{c}\mathbf{N}^{\circ} \text { DE } \\
\text { DEPÓSITOS } \\
\text { ATÉ 2011 }\end{array}$ & $\begin{array}{c}\text { PARTICIPAČÃO } \\
\text { NO TOTAL (\%) }\end{array}$ \\
\hline Sudeste & 18 & $53 \%$ & 22 & $50 \%$ \\
\hline Sul & 9 & $26 \%$ & 10 & $23 \%$ \\
\hline Norte & 3 & $9 \%$ & 3 & $7 \%$ \\
\hline Nordeste & 4 & $12 \%$ & 9 & $20 \%$ \\
\hline Centro-Oeste & 0 & $0 \%$ & 0 & $0 \%$ \\
\hline
\end{tabular}

Fonte: INPI, 2012. Elaboração própria.

A Tabela 2 demonstra que a região Sudeste permaneceu como a que mais solicitou registros de IGs nos dois períodos analisados. No entanto, sua participação no total de depósitos sofreu uma redução de 3\%. 
Coincidentemente, o mesmo comportamento foi encontrado na região Sul. Ela continuou com a posição de segunda maior depositante, e a redução em sua participação também foi de 3\% no total nos períodos comparados.

Responsável pela modificação no panorama de distribuição de depósitos regionais, o Nordeste, com cinco depósitos efetuados no período de agosto de 2010 a dezembro de 2011, foi a região que apresentou melhor desempenho. Sua participação cresceu $8 \%$, passando a ser responsável por 20\% dos depósitos.

A região Norte não realizou nenhum depósito no período de agosto de 2010 a dezembro de 2011. Dessa forma, sua participação caiu de $9 \%$ para $7 \%$, sendo que sua posição de quarta maior depositante permaneceu inalterada.

Por sua vez, a região Centro-Oeste permaneceu sem nenhum depósito até dezembro de 2011.

\section{Quais são os principais produtos requisitados?}

A seguir, passaremos à descrição de qual era o escopo de proteção requisitado nos pedidos de registros de IGs brasileiras. Dessa forma, poderemos identificar quais são os principais produtos/serviços que estavam sendo solicitados.

Eles estão dispostos na Tabela 3, que teve como critério para sua elaboração, visando evitar uma maior dispersão dos dados, a presença apenas de produtos/serviços que tivessem pelo menos dois depósitos. Dentro desse critério, seis foram os produtos que se destacaram. 
Tabela 3. Caracterização dos principais produtos nacionais depositados até 2011

\begin{tabular}{|c|c|c|c|}
\hline CATEGORIA & PRODUTO & ESTADO & $\mathrm{N}^{\circ}$ DE DEPÓSITOS \\
\hline & Café & Minas Gerais & 6 \\
\hline & & São Paulo & 1 \\
\hline & & Paraná & 1 \\
\hline & & Total & 8 \\
\hline \multirow[t]{5}{*}{$\begin{array}{l}\text { Bebidas } \\
\text { alcoólicas }\end{array}$} & $\begin{array}{c}\text { Aguardente } \\
\text { de cana tipo } \\
\text { cachaça }\end{array}$ & Rio de Janeiro & 1 \\
\hline & & Minas Gerais & 1 \\
\hline & Vinhos & $\begin{array}{l}\text { Rio Grande do } \\
\text { Sul }\end{array}$ & 3 \\
\hline & & Santa Catarina & 1 \\
\hline & & Total & 6 \\
\hline \multirow[t]{11}{*}{ Rochas } & Gnaisse & Rio de Janeiro & 3 \\
\hline & Mármore & Espírito Santo & 1 \\
\hline & Opala & Piauí & 1 \\
\hline & & Total & 5 \\
\hline & Água mineral & São Paulo & 1 \\
\hline & & Pará & 2 \\
\hline & & Total & 3 \\
\hline & Queijo & Minas Gerais & 2 \\
\hline & & Total & 2 \\
\hline & Algodão colorido & Paraíba & 2 \\
\hline & & Total & 2 \\
\hline
\end{tabular}

Fonte: INPI, 2012. Elaboração própria.

O café, além de pioneiro na iniciativa de depósito, apareceu ainda como sendo o produto com o maior número de depósitos, somando oito. O café foi, portanto, responsável por 18,6\% dos depósitos nacionais no período. E desses oito depósitos, seis pertencem ao estado de Minas Gerais. 
Em seguida, temos um agrupamento de dois produtos em uma única categoria: as bebidas alcoólicas. Divididas em aguardente de cana tipo cachaça e vinhos, totalizaram seis depósitos.

Interessante observar que, a exemplo do acontecido com o estado de Minas Gerais, houve também nesse setor uma concentração de depósitos. Nesse caso, o estado do Rio Grande do Sul foi o responsável por três depósitos dessa categoria, sendo todos para o produto vinho. As cachaças aqui encontradas são oriundas dos estados do Rio de Janeiro e de Minas Gerais.

As rochas aparecem como terceira categoria mais requisitada. Elas também abarcam produtos diferentes, sendo três depósitos para gnaisse, todos do Rio de Janeiro; um para mármore, do Espírito Santo; e um para opalas, do Piauí.

Interessante observar que esses são três dos quatro depósitos do estado do Rio de Janeiro. O outro depósito carioca foi Paraty para cachaça.

Por sua vez, o produto água mineral foi requerido três vezes, duas delas pelo estado do Pará e uma pelo estado de São Paulo.

Os demais produtos selecionados, queijo artesanal e algodão colorido, apresentaram dois depósitos cada um. Esses dois pedidos para cada produto foram depositados pelo mesmo estado, Minas Gerais e Paraíba, respectivamente.

Ao analisarmos o quadro encontrado, observamos que a presença dos produtos de origem agroalimentar é marcante. A predominância do produto café nos remete à história do País. Por muito tempo, o Brasil foi o maior produtor e exportador de café do mundo. E ainda hoje o somos, respondendo por 30\% do mercado internacional de café, com volume equivalente à soma da produção dos outros seis maiores países produtores, sendo o segundo mercado consumidor, atrás somente dos Estados Unidos (HALAL, 2008). 
Dessa forma, podemos afirmar que os dados aqui encontrados com relação aos depósitos de IGs no setor cafeeiro correspondem ao cenário econômico nacional, já que Minas Gerais, com especial destaque para a região do sul de Minas, é a liderança nacional da produção de café (Ibid.).

Nesse ponto, é interessante destacar ainda a presença significativa encontrada para o produto rochas. Tradicionalmente, nos países onde as IGs foram concebidas, o sinal era concedido praticamente com exclusividade a produtos agroalimentares, como já citamos. Dessa forma, esse produto, que não se enquadra de forma alguma na categoria agroalimentar tradicional, nos permite depreender que o Brasil encontra-se inovando no tema.

\section{Indicações geográficas nacionais registradas até dezembro de 2011}

Até dezembro de 2011 tínhamos 14 IGs concedidas:

- Vale dos Vinhedos para vinhos (RS);

- Região do Cerrado Mineiro para café (MG);

- Pampa Gaúcho da Campanha Meridional para carne (RS);

- Paraty para aguardentes tipo cachaça e aguardente composta azulada (RJ);

- Vale do Submédio São Francisco para uvas e mangas (BA/PE);

- Vale dos Sinos para couro acabado (RS);

- Região da Serra da Mantiqueira do estado de Minas Gerais para café (MG);

- Litoral Norte Gaúcho para arroz (RS);

- Pinto Bandeira para vinhos tintos e brancos e espumantes (RS);

- Região do Jalapão do estado do Tocantins para o artesanato em capim dourado (TO);

- Pelotas para doces finos tradicionais e de confeitaria (RS);

- Costa Negra para camarões (CE);

- Goiabeiras para panelas de barro (ES); e

- Serro para queijo (MG), o último reconhecimento do ano, ocorrido em dezembro de 2011 (Tabela 4). 
Tabela 4. IGs nacionais registradas até 2011

\begin{tabular}{|c|c|c|c|c|c|}
\hline NÚMERO & $\begin{array}{c}\text { NOME } \\
\text { GEOGRÁFICO } \\
\text { RECONHECIDO }\end{array}$ & ESTADO & PRODUTO & ESPÉCIE & $\begin{array}{c}\text { ESPÉCIE } \\
\text { DATA DA } \\
\text { CONCESSÃO }\end{array}$ \\
\hline IG990001 & $\begin{array}{l}\text { Região do } \\
\text { Cerrado } \\
\text { Mineiro }\end{array}$ & MG & Café & IP & $14 / 04 / 2005$ \\
\hline IG200002 & $\begin{array}{l}\text { Vale dos } \\
\text { Vinhedos }\end{array}$ & RS & $\begin{array}{l}\text { Vinho tinto } \\
\text { e branco e } \\
\text { espumantes }\end{array}$ & IP & 19/11/2002 \\
\hline IG200501 & $\begin{array}{c}\text { Pampa Gaúcho } \\
\text { da Campanha } \\
\text { Meridional }\end{array}$ & RS & $\begin{array}{l}\text { Carne bovina e } \\
\text { seus derivados }\end{array}$ & IP & $12 / 12 / 2006$ \\
\hline IG200602 & Paraty & RJ & $\begin{array}{c}\text { Aguardentes } \\
\text { tipo cachaça } \\
\text { e aguardente } \\
\text { composta } \\
\text { azulada }\end{array}$ & IP & $10 / 07 / 2007$ \\
\hline IG200701 & $\begin{array}{c}\text { Vale do } \\
\text { Submédio São } \\
\text { Francisco }\end{array}$ & $\mathrm{PE} / \mathrm{BA}$ & $\begin{array}{l}\text { Uvas de mesa } \\
\text { e manga }\end{array}$ & IP & 07/07/2009 \\
\hline IG200702 & Vale dos Sinos & RS & Couro acabado & IP & 19/05/2009 \\
\hline IG200704 & $\begin{array}{c}\text { Regiões da } \\
\text { Serra da } \\
\text { Mantiqueira } \\
\text { do estado de } \\
\text { Minas Gerais }\end{array}$ & $M G$ & Café & $\mathrm{IP}$ & $31 / 05 / 2011$ \\
\hline IG200801 & $\begin{array}{c}\text { Litoral Norte } \\
\text { Gaúcho }\end{array}$ & RS & Arroz & DO & $24 / 08 / 2010$ \\
\hline IG200803 & Pinto Bandeira & RS & $\begin{array}{l}\text { Vinhos tintos } \\
\text { e brancos e } \\
\text { espumantes }\end{array}$ & IP & $13 / 07 / 2010$ \\
\hline IG200902 & $\begin{array}{l}\text { Região do } \\
\text { Jalapão do } \\
\text { estado do } \\
\text { Tocantins }\end{array}$ & TO & $\begin{array}{l}\text { Artesanato em } \\
\text { capim dourado }\end{array}$ & $\mathrm{IP}$ & $30 / 08 / 2011$ \\
\hline IG200901 & Pelotas & RS & $\begin{array}{l}\text { Doces finos } \\
\text { tradicionais de } \\
\text { confeitaria }\end{array}$ & IP & $30 / 08 / 2011$ \\
\hline IG200907 & Costa Negra & CE & Camarões & DO & $16 / 08 / 2011$ \\
\hline IG201003 & Goiabeiras & ES & $\begin{array}{c}\text { Panelas de } \\
\text { barro }\end{array}$ & IP & $04 / 10 / 2011$ \\
\hline IG201001 & Serro & MG & Queijo & IP & $13 / 12 / 2011$ \\
\hline
\end{tabular}

Fonte: INPI, 2012. Elaboração própria. 
A análise da Tabela 4 nos permite verificar que, apesar do café, conforme apresentado na Tabela 3, ser o produto com o maior número de depósitos, ele conseguiu obter apenas duas concessões até dezembro de 2011.

Dessa forma, o setor cafeeiro é responsável por 18,6\% de todos os depósitos nacionais, mas, ao analisarmos sua presença nos registros, encontramos um decréscimo, com o café correspondendo a $14 \%$ do total registrado.

O vinho, por sua vez, é o produto que faz o caminho inverso e se destaca nesta análise. Responsável inicialmente por cerca de $9 \%$ do total de depósitos nacionais, passa a responder pelos mesmos $14 \%$ dos registros concedidos ao café, posto que possui dois registros, igualmente.

Outro importante aspecto a se observar é que esses dois registros do setor vinícola pertencem ao estado do Rio Grande do Sul. Esse estado depositou, ao todo, três depósitos para vinhos. O terceiro depósito, ainda não analisado até o final de 2011, trata-se do depósito na modalidade denominação de origem para Vale dos Vinhedos. O mesmo nome geográfico já foi reconhecido como indicação de procedência, sendo, inclusive, a primeira IG brasileira concedida nos idos de 2002.

Retornando ao exame da Tabela 4, é importante também recordar que um dos registros brasileiros, o Vale do Submédio São Francisco para uvas de mesa e manga, é uma IG que abrange dois estados: Pernambuco e Bahia. Esse era o único caso do tipo existente até o final de 2011.

Além disso, possuímos ainda outros registros que merecem ser destacados. São eles: Região do Jalapão do estado do Tocantins, para artesanato produzido com o belíssimo capim dourado; Goiabeiras, para panelas de barro, no estado do Espírito Santo; Pelotas, para doces finos tradicionais e de confeitaria; e ainda o Vale dos Sinos, para couro acabado; os dois últimos oriundos do Rio Grande do Sul. 
Tais registros, devido ao escopo de sua proteção, diferenciamse dos demais registros geralmente encontrados ao longo do mundo, pois são usualmente direcionados a produtos de origem agropecuária, especialmente nos países europeus, conforme anteriormente disposto.

O Rio Grande do Sul, segundo lugar em depósitos, foi identificado como o estado com o maior número de registros: seis. Eles se dividem em dois para vinhos tintos e brancos e espumantes; um para carne bovina e seus derivados; um para couro acabado; um para arroz; e um para doces finos tradicionais de confeitaria.

Minas Gerais, o estado com mais depósitos, 12, possui três reconhecimentos, sendo dois para café e um para queijo.

Observamos também que a maior parte dos registros brasileiros, 12, é na espécie indicação de procedência. Possuímos apenas dois registros na espécie denominação de origem, que são Litoral Norte Gaúcho para arroz e Costa Negra para camarões. Portanto, as DOs são responsáveis por apenas $14,3 \%$ dos registros contra $85,7 \%$ das IPs.

a. 1 Comparativo dos produtos registrados

A exemplo do que foi feito nos itens acima, na Tabela 5 temos o comparativo dos produtos ou serviços registrados. Os moldes permanecem os mesmos.

Tabela 5. Comparativo das IGs registradas até 2011

\begin{tabular}{|c|c|c|c|}
\hline \multirow[t]{2}{*}{ CATEGORIA } & \multirow[t]{2}{*}{ PRODUTO } & \multicolumn{2}{|c|}{$N^{\circ}$ DE REGISTROS } \\
\hline & & Até 08.10 & Até 2011 \\
\hline & Arroz & 1 & 1 \\
\hline & $\begin{array}{c}\text { Artesanato em capim } \\
\text { dourado }\end{array}$ & & 1 \\
\hline Bebidas alcoólicas & $\begin{array}{c}\text { Aguardente de cana tipo } \\
\text { cachaça }\end{array}$ & 1 & 1 \\
\hline & Vinhos & 2 & 2 \\
\hline & Café & 1 & 2 \\
\hline
\end{tabular}




\begin{tabular}{|c|c|c|c|}
\hline CATEGORIA & PRODUTO & \multicolumn{2}{|c|}{ N$^{\circ}$ DE REGISTROS } \\
\hline & Camarões & & 1 \\
\hline & Carne bovina & 1 & 1 \\
\hline & Couro acabado & 1 & 1 \\
\hline & Doces finos & & 1 \\
\hline & Panelas de barro & & 1 \\
\hline & Queijo artesanal & & 1 \\
\hline TOTAL DE REGISTROS & Uvas de mesa * & 1 & 1 \\
\hline
\end{tabular}

Obs: Uva e manga, apesar de colocados como produtos separados, pertencem à mesma IG, a Vale do Submédio do São Francisco. Fonte: INPI, 2012. Elaboração própria.

A primeira conclusão que o exame da Tabela 5 apresenta é que houve um interessante aumento no número de IGs concedidas. Até agosto de 2010, o Brasil possuía apenas oito registros. Esse cenário teve o incremento de seis registros, e, dessa forma, em dezembro de 2011 tínhamos 14 IGs concedidas. Isso significa um acréscimo de 75\%.

Itens tais como artesanato em capim dourado, camarões, doces finos e de confeitaria, panelas de barro e queijo ganharam seus primeiros registros. Já o café ganhou seu $2^{\circ}$ registro no período.

O Rio Grande do Sul é responsável por aproximadamente $49 \%$ dos registros nacionais de IG. Apesar de continuar sendo uma representação significativa no cenário nacional, ela foi reduzida, pois em 2010 era de $57 \%$.

Cumpre informar que, até o mês de março de 2012, outras três IGs foram registradas. São elas: São João Del-Rei (MG), para peças artesanais em estanho; Franca, para calçados (SP); e Vales da Uva Goethe, para vinhos (SC). No entanto, por terem sido concedidos em 2012, eles fogem ao escopo do presente estudo. 


\section{Considerações finais}

Atualmente, credita-se às Indicações Geográficas (IGs) a possibilidade de servirem como ferramenta oficial para salvaguardar, valorizar e atestar os níveis de qualidade, além das singularidades regionais de produtos relacionados a fatores naturais ou humanos de uma área delimitada.

No entanto, desde a entrada em vigor da LPI em 1997 até dezembro de 2011, apenas 43 IGs nacionais foram solicitadas. 0 pico de depósitos foi no ano de 2010, quando encontramos 13 depósitos. No entanto, o ano seguinte apresentou um decréscimo considerável e apenas cinco depósitos foram realizados, voltando ao patamar de 2004. Conforme anteriormente exposto, podemos apenas supor que essa variação se deve à dependência de ações de fomento institucionais, devido às observações pessoais diárias. Um período maior de observações, assim como de análise do comportamento, fazse necessário para melhores considerações.

Destacamos ainda que, ao analisar os dados encontrados, precisamos dimensioná-los de acordo com as variáveis existentes. Isto é, não basta apenas centralizar o olhar no expressivo aumento de $75 \%$ no número de registros, se esse aumento, na verdade, corresponde em números crus que apenas passamos de oito para 14 IGs concedidas no período levantado.

Isso significa que, passado cerca de um ano, não houve mudança significativa no cenário brasileiro referente ao assunto, ao compararmos com trabalhos anteriormente publicados. Dessa forma, a figura da IG ainda permanece sendo subutilizada em nosso País, principalmente ao considerarmos a diversidade biológica natural somada à diversidade cultural brasileira. Somos fruto de um intenso processo de colonização miscigenatório que nos concede grande potencial de produtos e serviços com características peculiares, devido a sua origem particular, história e ao saber fazer local.

Se estendermos nossa comparação com outros países da Europa, tais como a França, onde a quantidade de IGs chega facilmente 
às centenas, poderemos ver como os números de IGs brasileiras reconhecidas ao final de 2011 ainda são diminutos.

No entanto, mais uma vez, devemos observar as variáveis ao realizar essa comparação. Se, por um lado, ao considerar apenas a extensão territorial francesa, reconhecidamente muito menor do que a nossa, pensamos que deveríamos ter um número de IGs superiores, por outro, ao observar que nosso País está reconhecendo legalmente as IGs há apenas 15 anos, enquanto os países europeus o fazem há muitas e muitas décadas, podemos facilmente compreender essa diferença.

Os autores compreendem que um dos maiores desafios a serem superados é tornar o sinal distintivo coletivo IG reconhecido pelo público, para que ele exerça efetivamente sua função de distintividade. Tal objetivo só poderá ser alcançado se permanecermos esclarecendo e divulgando as características desse ativo da Pl, assim como encorajando os produtores a se unirem com o objetivo de valorizarem sua produção e suas características coletivamente.

Acreditamos ainda que, muitas vezes, um exemplo prático bem sucedido pode servir de estímulo de forma mais eficiente do que diversas teorias. Dessa forma, esperamos que a experiência que estamos adquirindo ao longo do período com a implantação das IGs reconhecidas resulte no fortalecimento do conceito no País.

Por fim, tivemos ainda outros interessantes pontos encontrados neste estudo, dignos de serem mencionados e de reflexões mais apuradas:

1 - 46,5\% de todos os depósitos realizados até o final de 2011 pertenciam a apenas dois estados: Minas Gerais e Rio Grande do Sul;

2- No período analisado, Minas Gerais foi o estado com o maior número de depósitos. No entanto, esse não é o estado com o maior número de concessões, como seria de se supor. Isso porque seis das 14 IGs concedidas até o final de 2011 pertenciam ao estado do Rio Grande Sul, resultando assim na expressiva representação de 42,8\% dos registros; e 
3- A grande diferença encontrada entre os números de depósitos e registros de IPs em comparação com DOs. Nos registros, essa proporção é de $14,3 \%$ de DOs e, consequentemente, $85,7 \%$ de IPs.

Por que apenas dois estados responderam por $46,5 \%$ dos depósitos nacionais? Supomos que exista um maior entrosamento dos produtores dos estados de MG e do RS com órgãos de fomento, instituições de ciência e tecnologia e uma maior facilidade de trabalharem o associativismo local, o que resulta em mais depósitos.

Por que Minas Gerais requereu mais e recebeu menos? A hipótese seria que os depósitos realizados pelo estado estão deficientes no atendimento aos requisitos citados na Resolução Inpi $n^{\circ} 075$ de 28/11/2000, o que gera os arquivamentos, as exigências e/ ou o atraso no exame dos depósitos.

Por que essa suposta preferência por IPs nos depósitos? Supomos que é mais simples e rápido comprovar a reputação do que comprovar o vínculo com o meio ambiente, conforme solicitado pela DO. Esse tipo de comprovação implica estudos complexos que possam ser cientificamente reproduzidos, o que demanda tempo e recursos humanos e monetários extras.

Os dados encontrados geraram esses questionamentos. Foram sugeridas algumas hipóteses que devem ser alvo de outros estudos para serem comprovadas ou negadas.

Recebido 30/03/2012

Aprovado 28/12/2012 


\section{Referências bibliográficas}

BARBOSA. D. B. Uma Introdução à Propriedade Intelectual. Rio de Janeiro: Lumens Júris, 2003.

BARBOSA, P. M. S. Panorama das solicitações das Indicações Geográficas Brasileiras. In: SEMINÁRIO INTERNACIONAL DE INDICAÇÃO GEOGRÁFICA: PRODUTOS DE ORIGEM COMO ESTRATÉGIA DE DESENVOLVIMENTO, 2., 2010, João Pessoa. Anais... Disponivel em: <http://www.indicacaogeografica.ufsc.br/palestras/SIIG_2010_ Patricia\%20Borbosa_INPI.pdf>. Acesso em: 05 mar. 2012.

BRASIL. Lei $\mathbf{n}^{\circ} \mathbf{9 . 2 7 9}$, de 14 de maio de 1996. Regula direito e obrigações relativos à propriedade industrial. Disponivel em: <http://www. planalto.gov.br/ccivil_03/leis/L9279.htm>. Acesso em: 16 ago. 2011.

FIGUEIREDO, L. H. M.; PENTEADO, M. I. O. Patentes em biotecnologia. Patenteamento em biotecnologia agropecuária: cenário brasileiro. Biotecnologia Ciência e Desenvolvimento, n. 36, p. 32-39, 2006. Disponivel em: <http://www.biotecnologia.com.br/revista/bio36/ patentes_36.pdf>. Acesso em: 04 mar. 2012.

GIL, A. C. Como elaborar projetos de pesquisas. São Paulo: Editora Atlas S. A., 1994.

HALAL, S. L. M. Composição, Processamento e Qualidade do Café. 2008. 45f. Trabalho de Conclusão de Curso (Bacharelado em Química de Alimentos)- Faculdade de Química de Alimentos, Universidade Federal de Pelotas, Pelotas. Disponivel em: http://quimicadealimentos.files. wordpress.com/2009/08/cafe.pdf. Acesso em: 12 mar. 2012.

INPI - Instituto Nacional da Propriedade Industrial. Registro das Indicações Geográficas. Disponível em: <http://www.inpi.gov.br/ portal/artigo/registros_indicacao_geografica\#>. Acesso em: 03 mar. 2012.

LARSON, J. Relevance of geographical indications and designations of origin for the sustainable use of genetic resources. 2007. Disponivel 
em: <https://underutilized-species.org/Documents/PUBLICATIONS/ gi_larson_Ir.pdf $>$. Acesso em: 10 fev. 2012.

LIMA, A.; BAPTISTA, F. M.; BENSUSAN, N. Direitos Intelectuais Coletivos e Conhecimentos Tradicionais. In: LIMA, A.; BENSUNAN, N. (Orgs.) Quem Cala Consente? Subsídios para a proteção aos conhecimentos tradicionais. São Paulo: ISA, 2003. p. 203-213. Disponivel em: <http:// www.socioambiental.org/banco_imagens/pdfs/70.pdf>. Acesso em: 10 fev. 2012.

MOREIRA, A. C.; ANTUNES, A. M. S. Patentes. Extratos de plantas e derivados. Verdades e mentiras sobre a patenteabilidade no Brasil. Revista Biotecnologia Ciência \& Desenvolvimento, n. 33, p. 62-71, 2004. Disponivel em: <http://www.biotecnologia.com.br/revista/ bio33/patentes.pdf>. Acesso em: 10 fev. 2012.

PINHO, J. B. O Poder das Marcas. São Paulo: Summus Editorial, 1996.

RAMELLO, G. B. What's In A Sign ? Trademark Law And Economic Theory. Journal of Economic Surveys, Blackwell Publishing, v. 20, p. 547-565, 2006.

RANGNEKAR, D. The Socio-Economics of Geographical Indications. A Review of Empirical Evidence from Europe. 2004. UNCTAD-ICTSD Project on IPRs and Sustainable Development. Issue Paper n. 8. Disponível em: <http://ictsd.org/downloads/2008/07/a.pdf>. Acesso em: 16 fev. 2012.

SEN apud BRUCH, K.; AREAS, P. O. 2011. Políticas Públicas em Signos Distintivos: a promoção do desenvolvimento como liberdade por meio das Indicações Geográficas e Marcas Coletivas aplicadas ao estudo de caso da Associação Catarinense dos Produtores de Vinhos Finos de Altitude - ACAVITIS. Disponivel em: <http://nbcgib.uesc.br/nit/ ig/app/papers/Pol\%C3\%83\%C2\%ADticas\%20P\%C3\%83\%C2\%BAblicas\%20 em\%20Signos\%20Distintivos.pdf>. Acesso em: 10 fev. 2012. 
SOARES, J. C. T. Cachaça-Indicação geográfica, Indicação de Procedência, Denominação de Origem ou Marca de Certificação. Revista da ABPI, n. 87, mar./abr. 2007.

VARELLA, M. D. Biodiversidade: o Brasil e o quadro internacional. Revista Brasileira de Política Internacional, Brasília, v. 40, n. 1, p. $123-$ 141, jan./jun. 1997. Disponivel em: <http://www.scielo.br/scielo. php?pid=S0034-73291997000100005\&script=sci_arttext $>$. Acesso em: 10 fev. 2012. 